\title{
Coal Mining with Three-dimensional Stagger Arrangement Roadway Layout Method: a case study
}

\author{
Zimo Cui ${ }^{1, a}$, Jingli Zhao ${ }^{2}$, Xiaojian Tian ${ }^{3}$, Pengfei Wang ${ }^{4}$, Emmanuel Chanda $^{5}$ \\ ${ }^{1,3,4}$ School of Resource and Safety Engineering, China University of Mining and Technology, Beijing \\ 100083, China \\ ${ }^{5}$ School of Civil, Environmental \& Mining Engineering, University of Adelaide, 5005, South Australia \\ ${ }^{2}$ State Key Laboratory of Coal Resources and Safe Mining, China University of Mining and \\ Technology, Beijing 100083, China \\ aczm19910413@outlook.com
}

Keywords: stagger arrangement; 3-D; roadway layout; recovery ratio; thick coal seam

\begin{abstract}
This paper takes that several engineering examples of practical applications introducing the 3-D roadway layout of stagger arrangement method without coal pillars, which arranged the air intake roadway and air return roadway in different horizons, realizing the transformation of roadway arrangement from 2D system to 3D system. And expanding the original working face 31111 in coal seam 2\# of Zhencheng Mine as project background, the paper makes systematic analysis to the geological, technical and economic factors, applies this new mining roadway layout technology for raising coal recovery ratio and solving the problems about full-seam mining in thick coal seam synthetically according to theoretical study and mining practice.
\end{abstract}

\section{Introduction}

For a long time, slice mining method is traditionally given priority to in terms of thick coal seam mining. The introduction of the caving coal mining technology has made remarkable achievements and got rapid development in the past thirty years, however, there exists a series of technical problems to be solved, such as low ratio of coal mining recovery is one of them. The coal loss, especially at working face end transition supports, roof of section roadway and section pillar loss, are a long-standing problem $[1,2]$.

At the same time, under the top-coal drivage inevitably results in high risk areas of roadway ignition frequently [3], accounting for about two-thirds of total ignition number of full-mechanized caving mining. Moreover, coals at the top-coal caving working face end and roof of section entry are not released in time and fall onto the mine gob, becoming the primary factor of adjacent gob ignition hazard when mining the next working face. In addition, it does no good to top-coal gas emissions when arranging the return air roadway on coal seam floor. Non-pillar mining was difficult to implement, and many problems existed, such as the section coal pillars could be seriously damaged in the long wall mining practices of thick coal seams.

Based on the current theoretical researches[4, 5] and practices, the technology of 3D stagger arrangement roadway layout was proposed (see Fig. 1), which has developed a new complete mining process, namely three-section procedure containing the concepts of 'zero coal pillar', 'negative coal pillar' and 'new-type narrow coal pillar'[6]. Development of the method, relative scientific problems and engineering examples were analyzed, drawing a conclusion that this technology is a significant reform of mining method with vast application prospect.

\section{Stagger arrangement roadway layout system}

For both can be slice mining and can be an overall height of thick coal seam mining, the roadway layout of stagger arrangement method arranges the air intake section roadway and air return section roadway respectively in different layers of the thick coal seam, as shown in Fig. 1. 


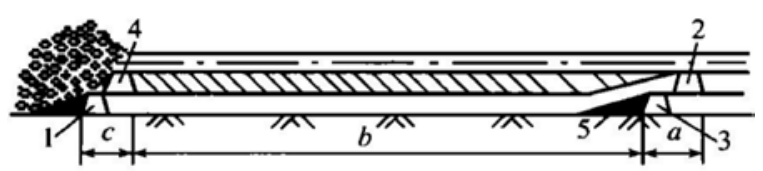

Fig. 1 The typical form of stagger arrangement roadway layout

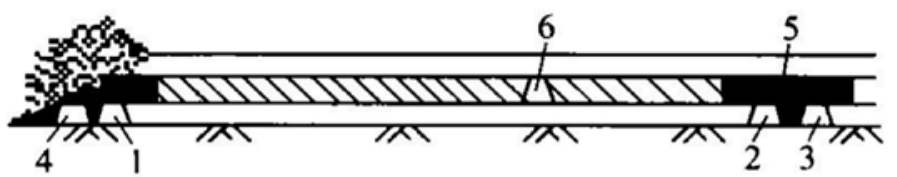

Fig. 2 The typical form of longwall top-coal caving roadway layout

1-air intake section roadway; 2-air return section roadway; 3- next air intake section roadway;

4-former air return section roadway; 5-coal loss; 6-gas drainage roadway

Stagger arrangement technology arranges section roadway 1 under the gob of the former working face in comparison to traditional caving mining roadway layout as shown in Fig. 2, which arranges these roadways on the same horizon in thick coal seam.

Coals have been mined at the top of transition supports and above section roadway 1 roof on the former working face as shown in Fig. 1. In Fig. 2, however, at the top of both section roadway 1, 4 and transition supports, coal caving lags behind the working face developing into loose abandoned float coals with easy air leakage property, meanwhile adjacent small coal pillar is destroyed under the roof pressure causing easily spontaneous combustion by air leakage; Another case leaves around $20 \mathrm{~m}$ section pillar between section roadway 1 and 4 giving rise to a large number of coal losses. The system in Fig. 1, however, not only has the end top-coal mined but also changes traditional section pillar into the triangular one, which greatly reduces coal losses.

Stagger arrangement roadway layout system enables to choose the most advantageous roadway position (as shown in Fig. 3) from the perspective of rock pressure distribution in different layers of stereo space in thick coal seam. After mining working face, there will appear stress redistribution in coals under roadway 2 and the floor strata.

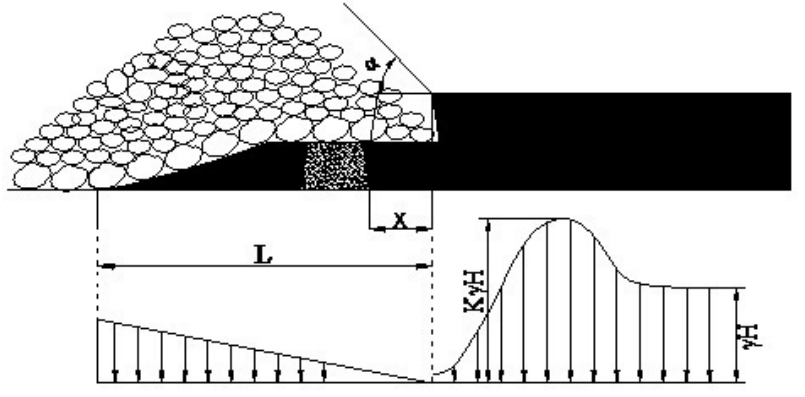

Fig. 3 Abutment stress distribution for one typical layout of stagger arrangement

Applying this conclusion enables to arrange air intake roadway 3 of the adjacent next working face under the gob which is on the left side of roadway 2, just in the position of the small stress in the stress-decreasing zone. There shall be the width of a general roadway between roadway 3 and roadway 2 in the horizontal direction. It is more greatly advantageous to the roadway drivage and maintenance in comparison to the traditional way of choosing roadway location.

The current sublevel caving mining methods, as shown in Fig. 2, generally leave a ' $T$ ' shape coal pillars for this roadway layout (as shown in Fig. 4 (a)), which is difficult to obtain good results from the perspective of the roadway maintenance and gob isolation. Coal pillar for roadway protection, in Fig. 2, is far higher than the roadway itself with coal loss on the top of roadways. The stress concentration, caused by top-coal mining in adjacent working face, is easy to get this narrow coal pillar with up to full thickness of coal seam fractured and crushed. Roof weighting impressing on roadways via top coal results in compression and deformation of roadways easily, which is unconducive to roadway maintenance (in Fig. 2). This traditional form of coal pillars will bring out more coal loss and poor effect of roadway maintenance. And the 
top-coal above roadways will fall into the gob in the form of loose float coals, becoming the spontaneous combustion hazard.

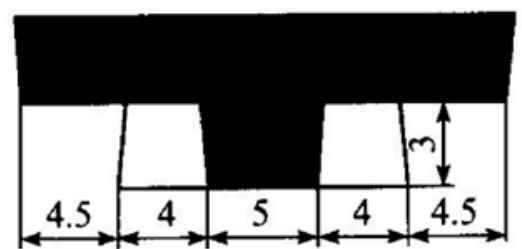

( a )

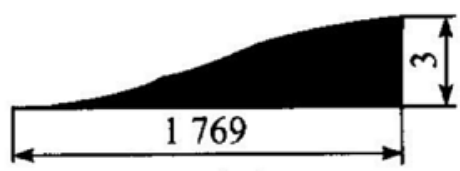

(b)

Fig. 4 Comparison of coal pillar loss

With stagger arrangement roadway layout system, as shown in Fig. 1, there shall be small triangular coal pillars with the same height of roadways on the gob side of the roadway 1 (as shown in Fig. 4 (b)), and coal rocks in working face on the other side of roadway 1. The top of the roadway is mined-out areas, having pressures sufficiently relieved, which is very favorable for roadway maintenance. Small triangular coal pillar beside the roadway bears little compression load and is difficult to crushed on account of having no direct link to the roof.

It is clearly illustrated in Fig. 4 that ' $T$ ' shape coal pillar loss covers an area of $81 \mathrm{~m}^{2}$, calculated in conditions of $6 \mathrm{~m}$ thickness of coal seam, $4 \mathrm{~m}$ width and $3 \mathrm{~m}$ height of the roadway, $3 \mathrm{~m}$ thickness of top coal, $5 \mathrm{~m}$ width of section coal pillar and $4.5 \mathrm{~m}$ width of coal loss above three rows of supports at each working face end. The triangular coal pillar loss, on the other hand, covers an area of $27 \mathrm{~m}^{2}$, which reducing $54 \mathrm{~m}^{2}$ compared with ' $\mathrm{T}$ ' shape one and calculated in conditions that the chute is vertically up $3^{\circ}$ for each section untill the maximum slope $15^{\circ}$, then drops by $3^{\circ}$ per each section. The top-coal covers an area of $450 \mathrm{~m}^{2}$ since the working face is 150 $\mathrm{m}$ long. The total recovery and top-coal recovery ratio, meanwhile, can be improved by $6 \%$ and $12 \%$, respectively. In conclusion, stagger arrangement roadway layout system can improve the recovery ratio by more over $10 \%$ in comparison with the traditional way keeping $15 \sim 20$ m length of section coal pillar.

\section{Numerical simulation}

This numerical simulation experiment took the fully mechanized caving face 31111 in coal seam 2\# of Zhencheng Mine as background. The working face of the inner stagger roadway layout in stagger arrangement method was compared with that of the traditional sub-level caving with $30 \mathrm{~m}$ long coal pillar, as shown in Figs. 5, 6. And their vertical stress and plastic zone distribution were shown in Figs. 7,8,9,10.

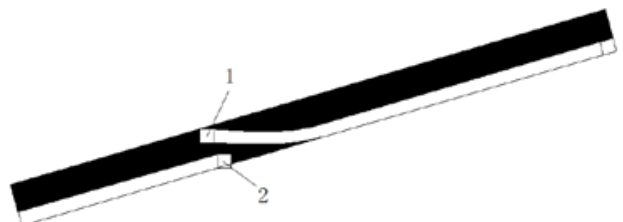

Fig. 5 Roadway layout in the inner stagger form

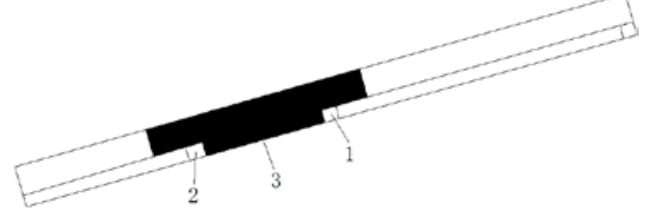

Fig. 6 Roadway layout in the traditional top-coal caving

1-air intake section roadway; 2- next air return section roadway; 3- ' $\mathrm{T}$ ' shape coal pillar loss The results of the inner stagger roadway layout are shown in Figs. 7, 8 when the next working face moved forward $60 \mathrm{~m}$ after the first mining face came to a completely stable state. 


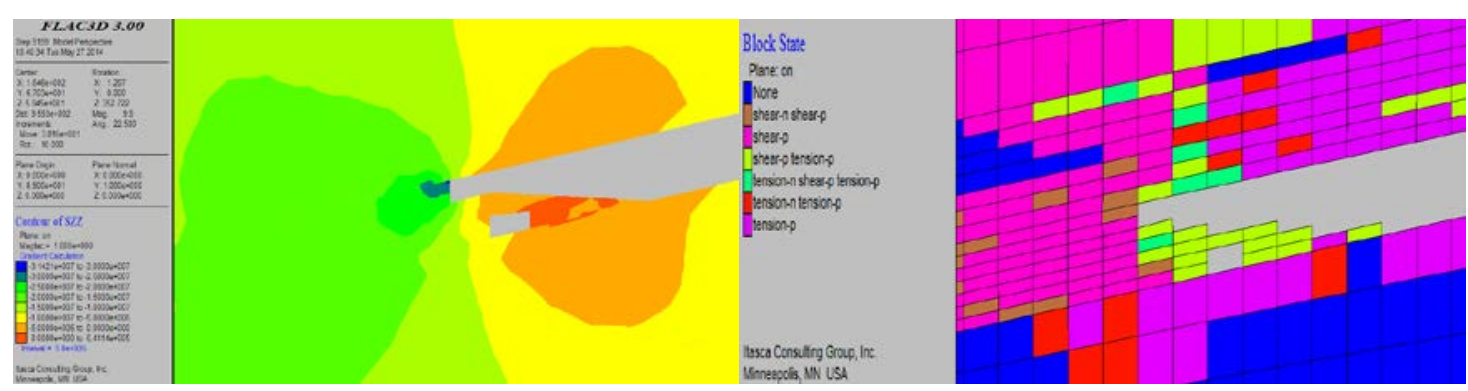

Fig. 7 Vertical stress distribution

Fig. 8 Plastic zone distribution

It illustrates that abutment pressure around the air return roadway, which locates in the triangular coal pillar of next working face, is smaller than in-situ rock stress with the inner stagger roadway layout. And the stress concentration degree becomes rather small when the stress is approximately 7.5 Mpa on the left side of triangular pillar and the pressure of roof and floor is close to $5 \mathrm{Mpa}$, even smaller. Plastic failure radius changes little and the pressure starts to increase from 5 metres away on the left side of air return roadway in the next working face. Stress concentration degree is relatively high within the scope of $15 \sim 35 \mathrm{~m}$ around coal rocks in the working face ends and concentration coefficient $\mathrm{k}$ is in the scope of $1.5 \sim 2$. 0 . Shear failure has already occurred in the top coal in advance, which is conducive to the sustainability of coal caving at working face ends. The air leakage in the working face deserves more attention when setting up supports considering that the roadway is along the gob now.

Triangular pillar, kept between two adjacent sections, bears small abutment pressure which is relatively mild since the concentration coefficient $\mathrm{k}$ is merely 0.25 . However, plastic deformation has occurred to the triangular pillar to a certain extent. And tensile fracture occurred to its surface within the scope of $1 \sim 2 \mathrm{~m}$, namely, coal rocks were fractured or crushed on the top and right side of air return roadway in the next working face. Moreover, tensile fracture also occurred to the air return roadway floor within the scope of $2 \mathrm{~m}$ to a certain extent. Roadways at the working face ends, therefore, needed to strengthen the management and their maintenance.

The air intake roadway that has already collapsed, had relatively large stress concentration on its upper left in the former working face. Its overlying roof strata, meanwhile, was in various degree of shear failure or tensile damage, which also illustrated that top-coal fracturing effect was quite well in the adjacent working faces with the stagger arrangement method. Especially the roof above the over-lapping areas of working faces could cave continuous evenly with greatly less degree of destruction to the surface environment.

The results of the traditional sub-level caving are shown in Figs. 9, 10 after the first working face's extracting and the gob caving came to a completely stable state, showing the vertical stress and the plastic zone distribution of coal pillar and air return roadway in the next working face.

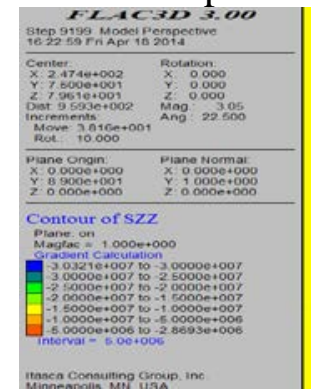

Fig. 9 Vertical stress distribution in traditional caving mining 


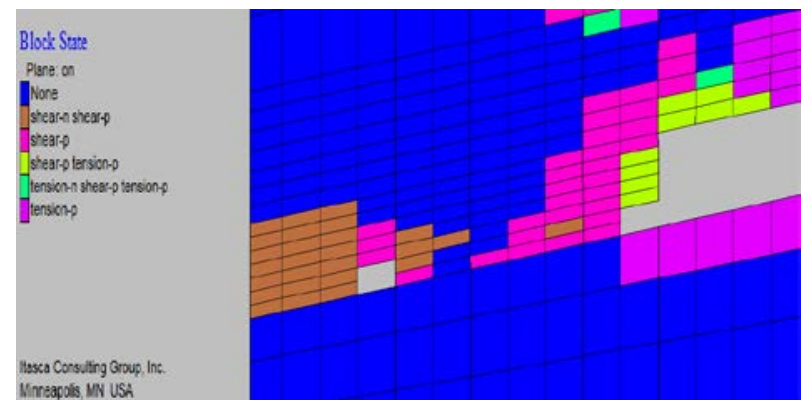

Fig. 10 Plastic zone distribution in traditional caving mining

It demonstrates that the pillar, kept between two adjacent sections, bears relatively larger abutment pressure in traditional roadway layout of the full-mechanized caving that arranging roadways in the same layer along the seam floor. The stress concentration degree inside the pillar, meanwhile, is also relatively higher since the concentration coefficient $\mathrm{k}$ varies from 2.25 to 3.00, which affects the stability of air return roadway in the next working face to a certain extent. Shear failure has occurred to both sides of the roadway under the dual effect of mining influence and superimposed stress from pillars and tensile failure occurred to the roof and lower right corner of the roadway. In conclusion, plastic failure zone of the roadway was in the range of $0 \sim 5$ meters. Coal pillar along the side of the goaf has been mostly crushed by the roof with slightly destruction in the middle part. Some parts keeping relatively intact, could protect the next working face and isolate the goaf in the former face, resulting in huge waste of the coal resources, however.

\section{Case study of this method}

There has been, as mentioned before, some successful engineering cases of practical applications of the 3-D roadway layout of stagger arrangement method. This paper only presents one of them in detail, including the relevant physical and numerical simulation.

Case 1:

The working face 2305 of Hebi Eight Mine, with coal thickness of 5.8 m, soft coal, $f=0.2 \sim$ 0.4 , absolute gas emission rate of $6.91 \mathrm{~m}^{3} / \mathrm{min}$ and the spontaneous combustion period of $3 \sim 6$ months, adopted stagger arrangement method [10] that arranged one section roadway along coal roof in lower strata and another section roadway along the floor in upper strata, which enabling that roadway excavation speed increased 2.46 times from previous $28 \mathrm{~m}$ per month to $97 \mathrm{~m}$ per month. Moreover, blast mining top-coal caving achieved a great success that extraction ratio was $81.1 \%$ in the working face and there was no coal spontaneous combustion accident in both roadways.

Case 2:

The working face 22202 in coal seam 2\# of Zhencheng Mine, with the thickness of $5.1 \mathrm{~m}$, length of $150 \mathrm{~m}$, extraction length of $680 \mathrm{~m}$, medium hard coal, $\mathrm{f}=2.1$, non-periodic weighting and low gas content of coal seam, adopted stagger arrangement roadway layout method [7], which enabling that extraction ratio of this working face was $89 \%$, improved by $12.6 \%$. This method also reduced costs of roadway drivage by $39.8 \%$ without spontaneous combustion and gas overrun.

Case 3:

The working face 18113 in coal seam 8\# of Zhencheng Mine, adoped inner stagger arrangement with 'negative coal pillar' [8] which achieved a great success. This method enabled that coal recovery ratio rose by more over $10 \%$, realizing non-pillar mining in thick coal seam. Other cases:

Wangjiashan Mine in Jingyuan town; Gushan Mine in Pingzhuang town; Huafeng Mine in Xinwen town, etc. 


\section{Summary}

Stagger arrangement roadway layout method, based on production practices in thick coal seam, integrates the existing mature technologies. And both roadway layout and excavation mining technology, with innovative and practical characteristics, not only retain the advantages of high production and efficiency in caving mining, but also absorb the experience of roadway drivage in slice mining.

Adopting this method, roadway driving speed can increase over one times with its cost decreasing by 30\%, meanwhile, achieving non-pillar mining and enabling roadway drivage and maintenance easier. Coal recovery ratio can rise over $10 \%$ while increasing the ratio of resource extraction. In terms of the safety of production, it enables to reduce coal loss at the end of working face, avoid high risk areas of roadway ignition frequently especially when excavating roadways under the roof without coal pillars.

In Fig. 1, the air return roadway 2, arranged in the upper layer along the roof, can effectively discharge the gas that accumulating in the upper corner of working face, which is very conducive to the safety of production.

Because of canceling coal pillar, this method changed the tough circumstances that extracting lower coal seams has to go through the stress concentration areas, and reduced the adverse impact with gradual surface subsidence.

\section{References}

[1] Wu J. (1998). The Review of Full-mechanized Caving Mining in Past 15 Years[J]. Ground Pressure and Strata Control. 1 9.

[2] Zhao J L. Meng X R. (1998). The Exploration of Sustainable Development of Full-mechanized Caving Mining[J]. Ground Pressure and Strata Control. 29 31.

[3] Zhao J L. (1997). Some Views on Development of Current Sub-level Caving Mining[J]. Coal. 04:17 18.

[4] A C Бурчаков. H K. Kovalchuk A B. (1982). Mining Technology[M]. China Coal Industry Publishing House. 386 388.

[5] Zhao J L. (1998). The Caving Mining Technology and Research on Application of Comprehensive Mine Evaluation[D]. China University of Mine and Technology. 2 4.

[6] Zhao J L. Wu J. (2002). Stagger Arrangement Technology in Thick Coal Seam[P]. ZL98100544.6, 2002-01-23.

[7] Li Y H. (2003). Study on Mining Technology of Zhencheng Mine Coal Seams[D]. China University of Mine and Technology. 41 50.

[8] Fan X M. (2013). Study on Application of Stagger Arrangement Roadway Layout in Xishan Mine[M]. China Coal Industry Publishing House. 73 78. 